\title{
Next Generation Innovation Policy and Grand Challenges
}

\begin{abstract}
The paper explores transformative ways to address Grand Challenges, while locating them in a broader diagnosis of ongoing changes. Coping with Grand Challenges is a challenge in its own right, for policy as well as for science, technology and innovation actors. The paper presents building blocks for a next generation of innovation policies, and it discusses the opportunities offered by new constellations of actors and their concertation. Future innovation policy designs can build on 'creative corporatism', a concept in which governments (or related international alliances) can adopt the crucial role of facilitating broader, more diverse ‘varieties of cooperation' in advanced capitalist economies.
\end{abstract}

Key words: Innovation policy; Grand Challenges; Governance; Transformation; Concertation

\section{Introduction}

One could consider the move towards a so-called challenge orientation, often in relation to Grand (Societal) Challenges, as a key part of the next generation of science, technology and innovation policy. Indeed, that might well be the case, both as a description of what is happening, and as a diagnosis of what is desirable. Such a dual mode of thinking and analysis is actually presaged in the notion of a 'next generation'; something that happens, as well as something that carries a promise for the future. One can then inquire the options and limitations of governance to realize the promise.

This is important because the governance challenge of addressing Grand Challenges is all too often flattened by reverting to traditional science, technology and innovation policy approaches. One example is the December 2015 Lund Declaration revisiting the original Lund Declaration of 2009, including the curious assertion that addressing Grand Challenges primarily requires doing excellent research. ${ }^{i}$ The challenge of addressing Grand Challenges is much broader than a next stage in mission orientation and priority setting. This point has been made before (Foray et al. 2012; JIIP 2012), but we want to pursue it further. We regard Grand Challenges as being transformative in the sense that they are part of overall societal development rather than just arguments for setting priorities in ongoing research and innovation systems (in policies, in practices). Grand Challenges are also occasions (and incentives) for new constellations of innovation actors to emerge and become active. Public-private partnerships, when transformative, are an earlier example of such dynamics.

Addressing Grand Challenges is a challenge in its own right, for policy as well as for science, technology and innovation actors. And it requires willingness to explore varieties of extant and new approaches. Thus, it is a site to explore what a next generation of innovation policy could look like. In the following, the notion 'innovation policy' is used to capture a broad scope of science, research, technology, and innovation-related policy initiatives. ${ }^{\text {ii }}$ Our analysis and diagnosis in this paper does not focus on directionality (Lindner et al. 2016) and demand-oriented instruments as such (Edler and Georghiou 2007; Edquist et al. 2015), but it offers a perspective in which directionality and demandoriented instruments of innovation policy can be repositioned. Thereby we will focus on options and limitations of governance, rather than on particular old or new policy instruments.

We will proceed in two steps. First, we discuss what we see happening already which indicates the emergence of a next generation of innovation policy. Second, we use the challenge of addressing Grand Challenges to identify important approaches that may well be valuable beyond the specific issues of Grand Challenges. 


\section{An emerging next generation of innovation policy}

Many present-day challenges (Grand or otherwise) are too complex to be addressed in versions of a 'command and control' mode. There will still be roles for central, more or less authoritative actors, like governments, but their action would be more like modulation of ongoing dynamics (Rip 2006) and versions of nudging. ${ }^{\text {iii }}$ Also, a substantial part of governance as it actually happens is de facto governance, that is, the guidance is effectuated embedded in evolving social ordering when there is some legitimacy (Rip 2010). This implies that a next generation of innovation policy cannot just be considered in its own right, as another game between policy actors and policy subjects (for earlier 'generations' see Rothwell and Zegveld 1981; Boekholt 2010). ${ }^{\text {iv }}$ The practices, promises and expectations of innovation activities and their contribution to socio-economic development are changing; the politics, policies and related instruments to govern innovation are evolving; and so do the theories which explain, legitimize, and evaluate innovation policy. And practice, policy, and theory co-evolve (another metaphor, with the same thrust, is the 'innovation policy dance', Kuhlmann et al. 2010).

Given this framing of innovation policy, it is more important to inquire into ongoing changes rather than having detailed debates on the value of one or another policy instrument. Or better, make sure that such detailed debates (which do serve a purpose, of course) are embedded in a consideration of ongoing changes. We will be somewhat impressionistic, but also look at a few interesting cases to see what can be learned from them: as it were, vignettes of a new generation of innovation policy. In the next section, where we discuss Grand Challenges as a further vignette, we take a forward looking perspective, identifying what would be required if the next generation is to deliver its promises.

One striking phenomenon is how new actors are joining policy arenas and public debates, and entering newly emerging spaces (Rip and Joly 2012) more generally, transcending the scope and involvement of 'classical' innovation policy 'stakeholders' (Kuhlmann 2001). Examples of such new actors in thematic domains like sustainable energy production and consumption include, for instance, not only 'classical' environmentalist groups but also local energy initiatives (Arentsen and Bellekom 2014); in health-related domains we find patient organisations, often in collaboration with philanthropic organisations proactively shaping debates and agendas (Boon et al. 2011). One could characterize what is happening as that agency appears no longer as mainly centralised (e.g. by national government) but as distributed, and driven by institutional entrepreneurs (Battilana et al. 2009), including civil society organisations.

We note that the issue of distributed agency is actually more complex, because central government has always included elements of delegation, territorial delegation, of course, but also sectoral as in neocorporatism (Schmitter 1985). Corporatism may be different in the form of participation compared with present opening-ups, but not different in principle. ${ }^{v}$ One of us (AR), referring to possible effects of institutionalization of Constructive Technology Assessment exercises, has noted that it would bypass central decision making, and thus create new forms of neo-corporatism (hopefully, more reflexive than traditional neo-corporatism) (Fischer and Rip 2013).

New actors, as well as existing actors in changing contexts (for example, firms involved in disruptive innovation) require resources (financial, media attention, others) and legitimation (including 'social licence to operate'). Putting forward explicit directionality, such as the ambition to address Grand Societal Challenges, can work as a resource and help to establish legitimacy. While one can start analysing this process with the help of the Advocacy Coalition Framework (Sabatier and JenkinsSmith 1993), directionality claims ‘towards transformation' exceed the classical setting of government and stakeholder actors and agenda-setting routines. ${ }^{\mathrm{vi}}$

Directionality as a resource for innovation policy articulation and agenda-setting emerges from heterogeneous sources and spaces. Interestingly, there are now calls to transform innovation (to address challenges more effectively) and have better innovation governance, including new constellations of actors. ${ }^{\text {vii }}$ Such moves are part of evolving de facto governance arrangements (Rip 2010). Directionality can turn into strategies, but these are patterns (de facto) rather than intentional strategies (Mintzberg and Waters 1985). Institutional entrepreneurs (governmental, industrial, as well as societal) can modulate de facto governance and nudge publics, media, politics into desired 
directions. In some environments, for example in the Nordic countries, emerging strategies with new innovation actors can also turn into more deliberate strategic agreements between organised actors: 'creative corporatism' stimulates "institutionalized cooperation among organized economic actors to invest in new supply-side resources, including venture capital, skill formation, and research” (Ornston 2012). This indicates that there are openings for change in the locus of responsibility and accountability, as part of the emergence of new constellations.

A related key observation is about the phenomenon of 'concertation' as a form of coordination by mutually taking actions of others into account and pro-actively adjust, thus creating the basis for concerted action. This horizontal coordination can be contrasted with vertical coordination, that is, orchestration by a central actor. Of course, this is not a complete dichotomy. There will be attempts at 'orchestration' by different actors, with various success. Concertation in practice will look like a patchwork. viii So our understanding of concerted action differs from the older neo-corporatist understanding of welfare state governance, in particular in Germany in the 1960s and 1970s (e.g. Lehmbruch 2003), not at least in labor policies (e.g. Hudson 1980; Compston 2003). Rather, concertation can be considered as a governance mode of "broader, more diverse 'varieties of cooperation'” in advanced capitalist economies (Ornston and Schulze-Cleven 2015, 575).

An example of new spaces for concertation are the European Technology Platforms, some of them leading on to Joint Technology Initiatives. They were set up from 2004 onwards, building on existing networks and initiatives and stimulating new ones. Strategy documents would be created identifying challenges, coordination would occur, and - hopefully - action taken. The themes often show a technology supply orientation, but there are references to broader issues like sustainability (Fresco et al. 2015). A recent example of concertation are the German-Dutch e-mobility concertation efforts: governments, incumbent car producers, new companies, societal organisations interact with a collective goal in mind. ${ }^{\mathrm{x}}$

To conclude this tour d'horizon of developments which may add up to a next generation of innovation policy, we discuss two vignettes of new innovation policy with a conscious attempt to work with new constellations of actors, and variable geometries of government responsibility. The German High Tech Strategy (BMBF 2014), since 2006, can be interpreted as a case of deliberate concertation of old and new actors, facilitating assemblage of heterogeneous capacities and capabilities, including social innovation, and by now claiming to address Grand Challenges (Dachs et al. 2015). While the Federal Ministry for Education and Research (BMBF) has a leading role, the Strategy works across the Federal level. The website lays out the ambitions:
"The new High-Tech Strategy stands for the aim of moving Germany forward on its way to becoming a worldwide innovation leader. (...) This is because innovative solutions are the factors that drive our prosperity and support our quality of life. They (...) make it possible to find creative answers to the urgent challenges of our time - including challenges in such areas as sustainable urban development, environmentally friendly energy, individualised medicine and the digital society.
(...) We are emphasising an expanded concept of innovation that includes not only technological innovation but also social innovation - and that includes society as a central player. We are looking at the big picture and conceptually putting those things together that really belong together." ${ }^{x}$

The first two phases of the High Tech Strategy (2006-2013) were rather corporatist efforts to coordinate more or less existing streams of public and public-private activities across ministerial departments and levels, having them form "Research Alliances", and stimulating further funding. ${ }^{\text {xi }}$ In the third phase though, since 2014, new actors became involved at the project level (not at the level of the "Research Alliances"), an effort to broaden the legitimation basis of the High Tech Strategy. Social innovation and interdisciplinary R\&D became more important, which links up with a strong problemorientation (focusing on "priority challenges", in spite of the name High Tech Strategy). The initiatives are supposed to be "technologieoffen" (open), rather than technology driven. More in particular, one of the Strategy's core elements is called "transparency and participation", with ingredients such as increased anticipatory efforts through "Innovation and Technology Analysis", promoting citizen science and a range of different formats of "Dialogues with Citizens" (Bürgerdialog), and expanded science communication, e.g. with a "House of the Future" (BMBF 
2014, 44ff). At the time of writing this paper, it was still too early to assess how serious and effective these ambitious but vaguely phrased measures have been implemented. The same holds for further relevant questions: to which degree is the new High Tech Strategy exceeding the previous high-tech orientation? Has the dominance of incumbent corporate actors become reduced and did new actors enter the stage effectively? How well is the Strategy imbedded in European and international alliances addressing Grand Challenges?

Another relevant vignette concerns the Dutch Top Sector Innovation Policy. This policy approach was introduced in 2011 to stimulate strong sectors in the Dutch economy, but was also an attempt to involve the sector as well as knowledge institutes by going for a novel version of public-private programmes. A lot of excitement (and some concern) was generated by the new policy, in the research and innovation system of the Netherlands as a whole. Key features of the Top Sector Policy are (1) delegation of further articulation of work programmes after the first selection of top sectors

('Innovation Agendas') to small Top Sector Teams, consisting of a leading scientist, well embedded in the knowledge institutes, somebody who can speak for business in the sector, a high level civil servant, and a fourth expert practitioner, for example representing small and medium-sized enterprises; (2) the fact that quite innovative directions and programmes were created in concertation (for example for High-Tech Systems and Materials, and for Horticulture and Starting Materials); and (3) the wider interest and uptake of links with the Top Sectors in the whole of the research and innovation system (partly because of incentives set by the government).

We note that such a broader uptake is actually required for addressing Grand Challenges.

\section{Addressing Grand Challenges: new constellations of actors and their concertation}

A third vignette, but still mostly in the future, is the move towards Grand Challenges, and attempts to adequately address them. If Grand Challenges are sometimes seen as just priorities for knowledge and innovation stimulation, and treated that way, say, through dedicated public funding, we are missing out on the actual challenges. They should be seen as open-ended missions, and missions concerning the socio-economic system as a whole, even inducing (or requiring) system transformation (see Kuhlmann and Rip 2014; Schot and Steinmueller 2016). Thus, Grand Challenges are ambitious, but not in the way the Manhattan Project (to develop an atom bomb) and the Apollo Project (to put a man on the moon) were. There, the challenge was technical (and organisational), and whether the goals were achieved or not was unambiguous (cf. also Foray et al. 2012). Grand Challenges, though, pertain to heterogeneous elements and forces, which have to be mobilised, guided and integrated, and include social innovation. Many different actors need to be involved, and the perspectives on what is the problem and what constitutes its resolution differ across various societal groups. Also, we see both "drivers of novelty and innovation as well as processes of capture and co-optation... involved" (Kallerud et al. 2013, 4), so Grand Challenges policies have to cope with contestation, non-linearity and bifurcations in developments. This is not a message of despair, but it does imply that our present understandings, instruments and practices of innovation policy (see for an overview Edler et al. 2016) are not sufficient to address Grand Challenges. A next generation of innovation policy is necessary, and the debate on, as well as concrete attempts to address Grand Challenges, is a site to explore what such a next generation could be. ${ }^{\text {xii }}$

Situations where there is an open-ended mission, evolving over time, partly because of the work that is done to address the mission, are not limited to Grand Challenges. This is one of the reasons why the notion of 'tentative governance' has been introduced to capture "provisional, flexible, revisable, dynamic and open approaches that include experimentation, learning, reflexivity, and reversibility" (Kuhlmann et al. 2018). One can see elements of 'tentative governance' in the suggestions of the JIIP (2012) Report "Investing in Research and Innovation for Grand Challenges" to the European Research Advisory Board, in particular in its emphasis on concerted action and adaptive programming. We add further considerations on concertation, including a discussion of new constellations of actors.

The notion of 'concertation' (which is about governance) was discussed already in Section 1. It should be complemented by the notion of 'assemblage' which is about innovative sociotechnical 
configurations. Grand Challenges require innovation, but it is not innovation as traditionally studied and stimulated, with a bias towards supply push. It is not just about demand orientation either, but about novel ways of assembling and re-assembling heterogeneous bits of work (including traditional innovation) into evolving sociotechnical configurations that address a Grand Challenge, including modifying it. One can make a comparison with the move, particularly visible in the automotive industry, of (motor car) companies becoming assemblers rather than builders, and redefining their overall product in terms of (auto)mobility.

Our point is that actors who could play a central role in concertation to address a Grand Challenge should be assemblers rather than builders. Such a role can be taken by charitable foundations ${ }^{\text {xiii }}$, but one could also think of funding agencies (research councils) expanding on their broker role. ${ }^{\text {xiv }}$ Here, we are moving away from a focus on government and its responsibilities to consider the possibility of challenges (Grand or otherwise) being taken up in the R\&D and innovation system more generally, rather than being a response to government push. This is important because most of knowledge production and innovation take place outside the sphere of direct influence of government agencies. New constellations of actors can emerge this way (cf. the move towards open innovation).

Another relevant driver is the ongoing, diffuse societal agenda building occurring all the time, for example when actors (companies, also various government agencies) start referring to 'green energy', to create symbolic resources (legitimacy), but then become imprisoned by their own tactics: they have to provide evidence of relevant action so as not to lose legitimacy. Eventually, 'green energy' becomes a forceful repertoire, part of the culture of our late-modern societies.

The nature and constellation of actors in concerted actions towards Grand Challenges will differ depending on how the nature of the Grand Challenge is seen, or better, is constructed. One key difference, we submit, refers to what is called, in the climate change debate, mitigation versus adaptation: one could try to mitigate or change the drivers or causes of the changes that constitute the challenge, or seek to adapt to their effects (perhaps because the causes appear to be difficult or impossible to change). For the challenge of the ageing society, mitigation may not be in order, but for water supply, one would like to do some mitigation rather than just adaptation.

In all cases, there are good reasons to include a larger variety of actors, and consider new roles for traditional actors. The approach required to identify and to address Grand Challenges is to 'assemble', to create a more inclusive, socio-technical system-oriented approach. This can be achieved in several complementary ways. First, key actors should be involved, which implies that actor consortia should be public-private. Also, charitable foundations should play a key role, because they are free to move, and tend to go for public interest goals. Second, besides economic aspects social aspects and changes are a key part of addressing Grand Challenges, so social innovation will have to be considered, including ongoing debates on modes and directions of social innovation (Van der Have and Rubalcaba 2016). Third, intermediary organisations and spaces for interactions are important to enable and improve concerted action without having a master plan. In the course of such developments, existing organisations may transform themselves. For example, as we noted already, research funding agencies may go further than their traditional role of funding research proposals, now adding reference to a Grand Challenge, and becoming brokers, playing a role in defining and/or managing concerted actions (Kuhlmann and Rip 2016).

One could think of Grand Challenge consortia, public-private set-ups, including charitable foundations, being responsible for concertation and assemblage. A very visible example is the Bill and Melinda Gates Foundation, already pro-active in public health and developing countries, and creating a separate consortium with a few governments (the traditional candidates like Canada, Sweden and Switzerland, but also Brazil and India) and a few big firms, to support and orchestrate working towards this societal challenge.

The government role, apart from joining in the concertation, could be to offer legitimation, for example by creating spaces for such consortia. ${ }^{\mathrm{xv}}$ Government could also assure that there is regular reflection on the nature of the Grand Challenges and the role of various actors (and assure a link with democratic decision making). 


\section{Conclusions and implications}

We started this paper with the assumption that the current orientation to Grand Societal Challenges could be seen as an important building brick for a 'next generation' of innovation policy, both as a description of what is happening, and as a diagnosis of what is desirable. Therefore we presented a tour d'horizon of related developments adding up to a next generation of innovation policy and we have illustrated them with a few 'vignettes' of current and potential future policy initiatives.

Addressing Grand Challenges will in many cases require a transformation of wider system contexts (knowledge and innovation systems; socio-technical systems). The perceptions of what is 'problematic' and which transformation is necessary will depend on the 'nature' of different challenges; they will be contested, will be negotiated and will evolve over time. Hence Grand Challenges and related transformations will remain open-ended.

As a consequence, next generation innovation policies will no longer remain a responsibility mainly of governments but become an integral part of the functioning of knowledge and innovation systems which are transformed themselves, including new sponsors and new performing actors. Future innovation policy designs can build on 'creative corporatism', a concept in which governments (and/or related international alliances) will adopt the crucial role of facilitating broader, more diverse 'varieties of cooperation' in advanced capitalist economies. In this context we see three main tasks for governmental actors:

Meta-governance: Given the open-endedness of the ongoing transformations, with emerging new spaces for articulation and negotiation of problem views of diverse actors and innovative ways of coping with problems, governmental actors would have to foster 'meta-governance' as "organising the conditions for governance" (Jessop 2002: 242) by self-organisation, thus complementing the modes of market exchange and hierarchic command. Meta-governance will help to experiment with governance constellations that can be more or less productive in a particular context. This meta-approach to governance suggests that next generation innovation policies will be implemented in a 'tentative' way: tentative governance typically aims at creating spaces for probing and learning instead of stipulating options for actors, institutions and processes. It addresses political and organizational complexities and uncertainties with explorative strategies, instead of relying only on orthodox or preservative means (Kuhlmann et al. 2018).

Concertation and assemblage: The particular meta-governance arrangement we focus on is the move towards concertation by bodies at arm's length from central policy makers. We consider concertation as a form of coordination by mutually taking actions of others into account and pro-actively adjusting, thus creating the basis for concerted action. Governments (and their alliances) can adopt the role of a coordinating change agent who is trustable, non-partisan, and ready to invest. Concerted actions in open-ended transformative environments will require experimental and creative 'assemblages' of innovative sociotechnical configurations.

The success of such a move, for traditional institutions of science as well as semi-independent concertation bodies will depend on the context. Societal agenda building and credibility pressures are important for the articulation of, and action towards, Grand Challenges; the easy reference to 'green energy' can serve as an example: it is broader than demand orientation because there is not a concrete demand, but a diffuse concern and a willingness to refer to it when shaping actions and justifying them. Addressing Grand Challenges will then not just be taking up such open references and turn them into new priorities, or just arguments why a direction that is taken for other reasons can be legitimated. It is also about learning about their nature and ways to address them.

Capability and capacity building: Like present innovation policies also the next generation will have to draw on strong material and intellectual infrastructures. While governments move from orchestration to concertation, they remain responsible for the public interest, keeping two major tasks: (1) there is a continued if not increasing need for targeted investment (cf. Mazzucato 2015) in knowledge bases and market creation (not at least through demand-based policies). (2) Transformation related concertation require learning, with new capacities and capabilities. The evolution of openended missions (as to their nature, co-evolving with implementation) needs to be evaluated, not at least to create accountability in our democratic societies. Hence, concertating change agents need to 
build competence in 'navigation': diagnostic and prospective studies ('Strategic Intelligence'), and means for consulting stakeholders, for deliberation, for the moderation of negotiations, and the ability to package and perform. More in particular, such capability and capacities will have to be built for 'meso-level' actors, such as ministries, funding organisations, boards of research organisations, of companies, and of civil society organisations (Kuhlmann et al. 2015).

We started out saying that Grand Challenges are transformative, they are about system transformations, and we discussed how to address such challenges. The further, and deeper, implication is that the ongoing transformations, and the role our addressing of Grand Challenges plays in them, should be reflected and acted upon. Such reflexivity is a key element of a next generation innovation policy.

\section{References:}

Arentsen, M., Bellekom, S. (2014). Power to the people: local energy initiatives as seedbeds of innovation? Energy, sustainability and society, 4(1), 1-12.

Battilana, J., Leca, B., Boxenbaum, E. (2009). 2 How actors change institutions: towards a theory of institutional entrepreneurship. The academy of management annals, 3(1), 65-107.

BMBF, Federal Ministry of Education and Research (2014).The new High-Tech Strategy Innovations for Germany. Berlin: BMBF (http://www.bmbf.de/).

Boekholt, P. (2010). The evolution of innovation policy paradigms and its effects on research, technological development and innovation policy instruments. In: Smits, R.; Kuhlmann, S.; Shapira, P. (eds.): The Theory and Practice of Innovation Policy. An International Research Handbook, Cheltenham, UK (Edward Elgar), 2010, 333-359.

Boon, W., Moors, E.H., Kuhlmann, S., Smits, R.E. (2011). Demand articulation in emerging technologies: intermediary user organisations as coproducers? Research Policy, 40, 242-252.

Compston, H. (2003). Beyond corporatism: A configurational theory of policy concertation. European Journal of Political Research, 42(6), 787-809.

Dachs, B., Dinges, M., Weber, M., Zahradnik, G., Warnke, P., Teufel, B. (2015).Herausforderungen und Perspektiven missionsorientierter Forschungs- und Innovationspolitik. Expertenkommission Forschung und Innovation (EFI), Berlin: Studien zum deutschen Innovationssystem Nr. 12-2015 (http://www.efi.de/fileadmin/Innovationsstudien_2015/StuDIS_12_2015.pdf).

Edler, J., Cunningham, P., Gök, A., Shapira, P. (eds) (2016). Handbook of Innovation Policy Impact. Eu-SPRI Forum on Science, Technology and Innovation Policy series,Cheltenham, UK (Edward Elgar).

Edler, J., Kuhlmann, S. (2008). Co-ordination within fragmentation. Governance in knowledge policy in the German federal system. Science and Public Policy, 35, 4, 265-276.

Edler, J., Georghiou, L. (2007). Public procurement and innovation—Resurrecting the demand side. Research policy, 36(7), 949-963.

Edquist, C., Vonortas, N. S., Zabala-Iturriagagoitia, J. M., \& Edler, J. (Eds.). (2015). Public procurement for innovation. Edward Elgar Publishing.

Fisher, E., Rip, A.(2013). Responsible Innovation: Multi-level dynamics and soft intervention practices. In: Owen, R., Bessant, J. and Heintz, M. (eds.), Responsible Innovation. Managing the Responsible Emergence of Science and Innovation in Society. 165-183. Chichester: John Wiley \& Sons.

Foray, D, Mowery, D.C., Nelson, R.R. (2012). 'Public R\&D and social challenges: What lessons from mission R\& D programs?' Research Policy 41(10), 1697-1702.

Fresco, L.O.; Martinuzzi, A.; Anvret, M.; Bustelo, M.; Butkus, E.; Cosnard, M.; Hallen, A.; Harayama, Y.; Herlitschka, S.; Kuhlmann, S.; Nedeltcheva, V.; Pelly, R.F. (2015).Commitment and Coherence. Ex-PostEvaluation of the 7th EU Framework Programme (2007-2013); (http://ec.europa.eu/research/evaluations/index_en.cfm); DOI: 10.13140/RG.2.1.4192.0083.

Hudson, M. (1980). ‘Concerted action’: wages policy in West Germany, 1967-1977. Industrial Relations Journal, 11(4), 5-16.

Jessop, R. D. (2002). The future of the capitalist state. Oxford: Blackwell. 
JIIP (Joint Institute for Innovation Policy) (2012). 'Investing in Research and Innovation for Grand Challenges. Study to assist ERAB', Brussels: European Commission, January 2012.

Kallerud, E., et al. (2013). 'Dimensions of research and innovation policies to address grand and global challenges’, EU-SPRI Forum Position Paper (http://www.euspriforum.eu/key_missions/CPRI_Position_paper.pdf).

Krull, W. (2016). Public Private Partnerships Revisited. Science Finance, Bonn/Berlin/New York: Lemmens Medien, 12-17. .

Kuhlmann, S. (2001). Governance of Innovation Policy in Europe - Three Scenarios. Research Policy, vol. 30/6, 953-976; DOI: 10.1016/S0048-7333(00)00167-0.

Kuhlmann, S., Rip, A. (2014). The challenge of addressing Grand Challenges. A think piece on how innovation can be driven towards the "Grand Challenges" as defined under the European Union Framework Programme Horizon 2020, Report to ERIAB; DOI: 10.13140/2.1.4757.184.

Kuhlmann, S., Rip. A. (2015). New constellations of actors addressing Grand Challenges: Evolving Concertation. KISTEP Inside and Insight, Sept. 2015, 8-11, Seoul/Republic of Korea (ISSN 2288-9574).

Kuhlmann, S., Rip, A. (2016). Grand societal and economic challenges: A challenge for the Norwegian knowledge and innovation system. Oslo: Research Council of Norway.

Kuhlmann, S., Edler, J., Ordóñez-Matamoros, G., Randles, S., Walhout, B., Gough, C., Lindner, R. (2015). Responsibility Navigator, Karlsruhe: Fraunhofer ISI, www.responsibility-navigator.eu.

Kuhlmann, S., Konrad, K., Stegmaier, P.(2018).Tentative Governance in Emerging Science and TechnologyConceptual Introduction and Overview. Research Policy (Special Section, forthcoming).

Kuhlmann, S., Shapira, P., Smits, R. (2010). Introduction. A Systemic Perspective: The Innovation Policy Dance. In: Smits, R.; Kuhlmann, S.; Shapira, P. (eds.): The Theory and Practice of Innovation Policy. An International Research Handbook, Cheltenham, UK (Edward Elgar), 1-22.

Lehmbruch, G. (2003).Concertation and the structure of corporatist networks. In: Verhandlungsdemokratie, 103128. VS Verlag für Sozialwissenschaften.

Lindner, R. et al. (2016). Addressing directionality: Orientation failure and the systems of innovation heuristic. Towards reflexive governance. Karlsruhe (Fraunhofer ISI Discussion Papers Innovation Systems and Policy Analysis No. 52) ISSN 1612-1430.

List, F. (1856).National System of Political Economy, Philadelphia (J. B. Lippincott \& Company).

Mazzucato, M. (2015). The entrepreneurial state: Debunking public vs. private sector myths. Anthem Press.

Mintzberg, H., Waters, J. A. (1985). Of strategies, deliberate, and emergent. Strategic Management Journal, Vol. 6, No. 3, 257-272; http://www.jstor.org/stable/2486186.

Ornston, D. (2012). Creative Corporatism. The Politics of High-Technology Competition in Nordic Europe. Comparative Political Studies, doi: 10.1177/0010414012463881.

Ornston, D., Schulze-Cleven, T. (2015).Conceptualizing Cooperation Coordination and Concertation as Two Logics of Collective Action. Comparative Political Studies, 48(5), 555-585.

Rip, A. (2010). De Facto Governance of Nanotechnologies. In: Goodwin, M.; Koops, B. J.; Leenes, R. (eds): Dimensions of technology regulation. Wolf Legal Publishers, 285-308.

Rip, A., Joly, P. (2012). Emerging Spaces and Governance. A position paper for EU-SPRI.

Rothwell, R., Zegveld, W. (1981). Industrial Innovation and Public Policy: Preparing for the 1980s and the 1990s. London: Frances Pinter.

Sabatier, P. A., Jenkins-Smith, H. (1993). Policy change and learning: An advocacy coalition framework. Boulder: Westview.

Scharpf, F.W. (1997). Games Real Actors Play. Actor-Centered Institutionalism in Policy Research, Boulder, CO: Westview Press, 1997

Schot, J., Steinmueller, W.E. (2016). Framing Innovation Policy for Transformative Change: Innovation Policy 3.0. Brighton (SPRU working paper series).

Smits, R., Kuhlmann, S. (2004). The rise of systemic instruments in innovation policy. Int. J. Foresight and Innovation Policy (IJFIP), Vol. 1, Nos. 1/2, 2004, 4-32. DOI: 10.1504/IJFIP.2004.004621.

Smits, R., Kuhlmann, S., Teubal, M. (2010). A System-Evolutionary Approach for Innovation Policy. In: Smits, R.; Kuhlmann, S.; Shapira, P. (eds.): The Theory and Practice of Innovation Policy. An International Research Handbook, Cheltenham, UK (Edward Elgar), 417-448.

Schmitter, P. C. (1985). Neo-corporatism and the State. In: The Political economy of corporatism, 32-62. Macmillan Education UK. 
Van der Have, R., Rubalcaba, L. (2016). Social innovation research: An emerging area of innovation studies?, Research Policy 45/9, 1923-1935, http://dx.doi.org/10.1016/j.respol.2016.06.010.

Van der Meulen, B. (1998). Science policies as principal-agent games: Institutionalization and path dependency in the relation between government and science. Research Policy, 27(4), 397-414.

\section{Notes}

www.vr.se/lunddeclaration2015 (approached August 17, 2016).

ii Following Kuhlmann $(2001,954)$ who discussed 'innovation policies' "as the integral of all state initiatives regarding science, education, research, technology policy and industrial modernisation, overlapping also with industrial, environmental, labour and social policies. Public innovation policy aims to strengthen the competitiveness of an economy or of selected sectors, in order to increase societal welfare through economic success."

iii We say "versions of" nudging, because the recent interest in nudging focusses on behavioural incentives, for example in energy policy, based on the work of the UK Cabinet Office so-called "Nudge Unit"( https://www.gov.uk/government/organisations/behavioural-insights-team; and

http://www.behaviouralinsights.co.uk/ ), rather than on interactions and emerging patterns in society, which is the level at which addressing Grand Challenges plays out.

iv Even if such games are part of the dynamics, cf. principal-agent analysis (e.g. van der Meulen 1998). Cf. also Scharpf (1997) on games real actors play.

$\checkmark$ And the present notions of broad and disperse participation might actually, and ironically, imply a stronger role for the central state, as orchestrator of the participation, and selector of what to take up in eventual decisions. We're grateful to Jakob Edler to bring this point to our attention.

vivi An interesting question is how 'classical' this setting actually is. Probably it has never been classical (remember the at least implicitly innovation and transformation-oriented concepts and policy initiatives of figures like Friedrich List; see List 1856) except in historical phases of strong growth and/or sufficient institutional stability.

vii A recent example is move of the Science Policy Research Unit (SPRU) at the University of Sussex to address "Transforming Innovation" in its research and networking (it was the theme of its 50th anniversary conference, 7-9 September 2016), up to creating a 'Transformative Innovation Policy Consortium (TIPC)', a collaboration platform of SPRU with, the other founding organisations; Colciencias, the Government of Colombia's Department of Science, Technology and Innovation; the National Research Foundation in South Africa; and Forskningsradet: the Research Council in Norway. The Consortium's "objective ... to examine and expand on current innovation frames and approaches to assist in solving urgent social and economic issues of our time". The platform also seeks to engage in policy design and experimentation, training and skill formation. "The project involves building new platforms for a mutual learning process between the Global North and South and between research and policy" http://www.sussex.ac.uk/spru/newsandevents/2016/awards/consortium (accessed Sept. 12, 2016).

viii Concertation can be furthered with the help of road mapping, but road-mapping exercises do require a prior definition of the goal to be reached, which cannot be easily done in the case of Grand Challenges. Actual road-mapping exercises can lead to a discussion of the nature and values of the goals, however.

ix http://www.emobilitypartners.com/about/(approached April 1, 2017).

x http://www.hightech-strategie.de/de/The-new-High-Tech-Strategy-390.php (approached August 17, 2016)

xi 'The governance of Germany's public 'knowledge system' is characterised by a variety of coordination needs and modes in a layered and fragmented federal system. Competences are divided between horizontal sectoral ministries and agencies at the federal level and between federal level and the states (Länder), the latter being endowed with major competences in education and science policy. This fragmentation may have advantages regarding interfaces with stakeholders, but coordination between and within ministries is indeed insufficient when it comes to providing policy consistency and overall orientation." (Edler \& Kuhlmann, 2008, 265) In such a context the High Tech Strategy clearly is a pro-active coordination effort, orchestrated by the Federal Government, in particular the BMBF. Actually, in 2005/6 a BMBF State Secretary acted as an institutional entrepreneur, linking up with other ministries and key actors in the national research and innovation system, to realize the High Tech Strategy. 
xii There are precedents. When it comes to transformation-oriented innovation policy instruments, the concept of "systemic policies and instruments" (Smits \& Kuhlmann 2004) offers a useful approach, in particular those aiming at "structural change" through "re-shaping innovation systems (facilitating construction and deconstruction of subsystems, preventing of lock-in; supporting prime movers; ensuring that all relevant actors are involved); building cross-linking platforms and new spaces for learning and experimenting; stimulating demand articulation, strategy and vision development, providing and exploiting and infrastructure for distributed intelligence" (Smits et al. 2010, 431-432).

xiii Increasingly charitable foundations play active roles in public-private partnerships aiming at (transformative) innovation (Krull 2016).

xiv We have developed this last possibility in our commissioned study for the Norwegian Research Council (Kuhlmann and Rip 2016, p. 8-9), and noted that assembling has not played an important role in the research system, but that the capacity to do so will be increasingly important.

${ }^{\mathrm{xv}}$ 'Spaces' in this sense are characterized by spatiality (a social as well as a material space), by boundedness because of reference to boundaries, and by internal arrangements which depend also on the conditions for the space to survive in the wider world (Rip \& Joly 2012). 